\title{
Análise microscópica da resistência do arroz à queima das bainhas mediada pelo silício
}

\author{
Daniel Augusto Schurt; Ricardo Dutra Reis; Leonardo Araujo; Vivian Carré-Missio; \\ Fabrício Ávila Rodrigues (*) \\ Universidade Federal de Viçosa (UFV), Departamento de Fitopatologia, Av. Peter Henry Rolfs, s/n, 36570-900 Viçosa (MG), Brasil. \\ (*) Autor correspondente: fabricio@ufv.br
}

Recebido: 9/out./2014; Aceito: 2/dez./2014

\begin{abstract}
Resumo
A queima das bainhas, causada pelo fungo Rhizoctonia solani Kühn, é uma das mais importantes e destrutivas doenças que afetam a produção de arroz no mundo. Embora o silício (Si) seja capaz de reduzir a intensidade da queima das bainhas, os mecanismos de resistência mediados por esse elemento permanecem desconhecidos. Assim, este trabalho teve como objetivo investigar a nível microscópico o efeito do Si na resistência do arroz à infecção por R. solani. Plantas de arroz das cultivares BR-Irga-409 e Labelle foram cultivadas em solução nutritiva contendo 0 ou 2 mM de Si e inoculadas no estádio de máximo perfilhamento utilizando-se pedaços de palito de dente colonizados por R. solani. Ambos cultivares supridas com Si apresentaram intensa e homogênea deposição de Si nos tecidos das bainhas colonizados por R. solani. A maior concentração de Si nas bainhas de plantas de arroz de ambas cultivares contribuiu para reduzir os sintomas da queima das bainhas. Com o auxílio da microscopia de luz e da microscopia eletrônica de varredura, observou-se menor crescimento micelial do fungo sobre as bainhas foliares das plantas de ambas cultivares que foram supridas com Si. Secções das bainhas de plantas de ambos cultivares supridas com Si exibiram intensa autofluorescência nos tecidos próximos a regiões necrosadas devido a colonização por $R$. solani. Em conclusão, o suprimento de Si às plantas de arroz desempenhou um papel importante na redução dos sintomas da queima das bainhas.
\end{abstract}

Palavras-chave: Rhizoctonia solani, autofluorescência, microanálise de raios-X, microscopia de luz, microscopia eletrônica de varredura, nutrição mineral.

\section{Microscopic analysis of rice resistance to sheath blight mediated by silicon}

\section{Abstract}

Sheath blight, caused by the fungus Rhizoctonia solani Kühn, is one of the most important and destructive diseases affecting rice production in the world. Although silicon ( $\mathrm{Si}$ ) is able to reduce the sheath blight intensity, the mechanisms of resistance mediated by this element remain unknown. Thus, this study aimed to investigate at the microscopical level the effect of Si on rice resistance to infection by $R$. solani. Rice plants from cultivars BR-Irga-409 and Labelle were grown in nutrient solution containing 0 or $2 \mathrm{mM}$ of $\mathrm{Si}$ and inoculated the maximum tillering stage using pieces of toothpick colonized by R. solani. Both cultivars supplied with $\mathrm{Si}$ showed intense and homogeneous deposition of $\mathrm{Si}$ in the leaf sheaths tissue colonized by $\mathrm{R}$. solani. The highest Si concentration on the leaf sheaths of plants of both cultivars contributed to reduce the sheath blight symptoms. Using light microscopy and scanning electron microscopy, it was observed reduced fungal growth on the leaf sheaths of plants from both cultivars which were supplied with Si. Sections of the leaf sheaths of plants from both cultivars supplied with Si exhibited intense autofluorescence in tissues near to the necrotic areas due to R. solani colonization. In conclusion, the supply of Si to rice plants played an important role in reducing the sheath blight symptoms.

Key words: Rhizoctonia solani, autofluorescence, x-ray microanalysis, light microscopy, scanning electron microscopy, mineral nutrition.

\section{INTRODUÇÃO}

A queima das bainhas, causada pelo fungo Rhizoctonia solani Kühn, é uma das mais importantes e destrutivas doenças que afetam a produção de arroz no mundo $(\mathrm{Ou}$, 1985). A obtenção de cultivares de arroz com resistência a essa doença têm sido uma das metas nos programas de melhoramento genético (Li et al., 1995). No entanto, até o presente momento, nenhuma fonte de resistência completa à queima das bainhas foi encontrada (Li et al., 1995), o que leva a constante busca por alternativas de controle dessa doença.

O silício ( $\mathrm{Si}$ ), apesar de não ser considerado um nutriente essencial às plantas, destaca-se por reduzir a intensidade 
de doenças importantes em várias culturas, principalmente gramíneas e algumas dicotiledôneas como café, feijão, pepino e soja (Bélanger et al., 2003; Cruz et al., 2013, 2014; Domiciano et al., 2010; Guével et al., 2007; Ma, 2004; Rodrigues et al., 2003a,b). O aumento na concentração de Si nos tecidos das plantas de arroz tem sido associado com a resistência à brusone, mancha marrom, podridão do colmo, escaldadura, queima das bainhas e escurecimento dos grãos (Cacique et al., 2013; Datnoff et al., 1997; Hayasaka et al., 2008; Kim et al., 2002; Rezende et al., 2009; Rodrigues et al., 2003a,b; Schurt et al., 2013; Tatagiba et al., 2014).

Uma das hipóteses para a redução na intensidade das doenças pelo Si deve-se, em parte, ao depósito desse elemento na parede celular e abaixo da cutícula, formando uma dupla camada cutícula-sílica na folha do arroz (Ma \& Yamaji, 2006; Yoshida et al., 1962). Essa camada de sílica geralmente atua como uma barreira física que impede ou atrasa a penetração dos fungos (Hayasaka et al., 2008; Kim et al., 2002; Ma \& Yamaji, 2006; Yoshida et al., 1962). As células silicatadas também são observadas na epiderme e nos tecidos vasculares do caule, bainha, folha, além da casca do arroz (Ma \& Yamaji, 2006; Yoshida et al., 1962). Outra hipótese bastante discutida é que o Si pode potencializar mecanismos bioquímicos de defesa (Rodrigues et al., 2003b, 2004, 2005). Rodrigues et al. (2003b) demonstraram que plantas de arroz supridas com $\mathrm{Si}$ apresentaram um aumento na produção de compostos fenólicos e, consequentemente, maior resistência à brusone. Além disso, Rodrigues et al. $(2004,2005)$ verificaram que plantas de arroz supridas com Si e inoculadas com Pyricularia oryzae exibiram aumento na produção de fitoalexinas momilactonas A e B e uma maior ativação dos genes $\beta$-1,3-glucanase, peroxidase e PR-1.

A nível microscópico, diversos estudos têm demonstrado a importância do Si para potencializar a resistência de plantas a patógenos (Bélanger et al., 2003; Cruz et al., 2014; Koga et al.,1988; Rodrigues et al., 2003b). Rodrigues et al. (2003b) investigaram a nível ultraestrutural a interaçáo arroz-P. oryzae e observaram a ocorrência de muitas hifas fúngicas aparentemente mortas e envoltas por compostos fenólicos em tecidos foliares de plantas supridas com Si. Cruz et al. (2014), utilizando microscopia eletrônica de varredura acoplada com espectroscopia de raios-X, verificaram que o suprimento de $\mathrm{Si}$ às plantas de feijoeiro contribuiu para reduzir os sintomas da antracnose, devido a altas concentraçóes foliares de enxofre, Si e potássio próximo às nervuras infectadas por Colletotrichum lindemuthianum. Koga et al. (1988) observaram que o acúmulo de Si insolúvel nas células epidérmicas de plantas de cevada infectadas com Blumeria graminis f. sp. hordei foram associadas com um aumento na intensidade de autofluorescência e maior resistência ao míldio pulverulento. No entanto, apesar desses resultados promissores, ainda não se sabe como as plantas de arroz supridas com $\mathrm{Si}$ respondem à infecção por $R$. solani a nível microscópico. Assim, este trabalho teve como objetivo investigar, a nível microscópico, o efeito do Si na resistência do arroz à infecção por $R$. solani.

\section{MATERIAL E MÉTODOS}

\section{Crescimento das plantas de arroz}

Plantas de arroz foram crescidas de acordo com a metodologia de Schurt et al. (2013). Sementes de arroz dos cultivares BR-Irga 409 e Labelle, suscetíveis à $R$. solani, foram esterilizadas em hipoclorito de sódio $10 \%$ (vol/vol) por dois minutos, lavadas em água destilada por 3 min e colocadas para germinar em papel germiteste umedecido. Os rolos de papel germiteste foram colocados em câmara de germinação a $25^{\circ} \mathrm{C}$ por seis dias no escuro. As plântulas cresceram, por sete dias, em vasos plásticos com solução nutritiva contendo todos os nutrientes em suas concentraçóes reduzidas pela metade da concentração final. Após esse período, as plantas foram transferidas para vasos plásticos contendo cinco litros de soluçáo nutritiva de Hoagland \& Arnon (1950) com algumas modificações, constituída de $1 \mathrm{mM} \mathrm{KNO}_{3} ; 0,25$ $\mathrm{mM} \mathrm{NH}_{4} \mathrm{H}_{2} \mathrm{PO}_{4} ; 0,1 \mathrm{mM} \mathrm{NH}_{4} \mathrm{Cl} ; 0,5 \mathrm{mM} \mathrm{MgSO}_{4} .7 \mathrm{H}_{2} \mathrm{O}$; $1 \mathrm{mM} \mathrm{Ca}\left(\mathrm{NO}_{3}\right)_{2} \cdot 4 \mathrm{H}_{2} \mathrm{O} ; 0,3 \mu \mathrm{M} \mathrm{CuSO} \mathrm{C}_{4} \cdot 5 \mathrm{H}_{2} \mathrm{O} ; 0,33 \mu \mathrm{M}$ $\mathrm{ZnSO}_{4} .7 \mathrm{H}_{2} \mathrm{O} ; 11,5 \mu \mathrm{M} \mathrm{H}_{3} \mathrm{BO}_{3} ; 3,5 \mu \mathrm{M} \mathrm{MnCl}_{2} .4 \mathrm{H}_{2} \mathrm{O}$; $0,014 \mu \mathrm{M}\left(\mathrm{NH}_{4}\right)_{6} \mathrm{Mo}_{7} \mathrm{O}_{2} \cdot 4 \mathrm{H}_{2} \mathrm{O} ; 25 \mu \mathrm{M} \mathrm{Na} 2$ EDTA e 25 $\mu \mathrm{M} \mathrm{FeSO}_{4} .7 \mathrm{H}_{2} \mathrm{O}$. O Si, fornecido como ácido monosilícico foi obtido pela passagem do silicato de potássio através de resina de troca de cátions (Amberlite IR-120B, $\mathrm{H}^{+}$forma, Sigma-Aldrich, São Paulo, Brasil) (Ma et al., 2002). As concentraçóes de Si utilizadas foram de 0 e $2 \mathrm{mM}$. A cada quatro dias, a soluçáo nutritiva foi trocada e o $\mathrm{pH}$ foi aferido a cada dois dias e mantido entre 5,5 e 6 .

\section{Inoculação com R. solani e avaliação da doença}

As bainhas das plantas foram inoculadas com o isolado de $R$. solani CNPAF $R s-1$ (AG-1 IA) aos 60 dias após o transplantio (estádio de máximo perfilhamento) para solução nutritiva. Escleródios do fungo foram preservados em sílica gel. Após o crescimento do fungo obtido a partir de escleródios em meio de cultura batata-dextrose-ágar (BDA), transferiram-se discos do meio contendo micélio para novas placas de Petri contendo o meio BDA. Na superfície do meio de cultura contido em cada placa de Petri colocaram-se pedaços de palito de dente de $1 \mathrm{~cm}$ de comprimento que serviram como suporte para o crescimento do fungo. Os pedaços de palito de dente, previamente lavados em água quente para remover possíveis substâncias tóxicas, foram colocados em frascos contendo o meio BDA e autoclavados por 20 minutos (Rodrigues et al., 2001). As placas contendo micélio crescendo sobre e no interior dos 
palitos permaneceram em câmara de crescimento $\left(25^{\circ} \mathrm{C}\right.$, fotoperíodo de 12 horas luz) por cinco dias. A segunda bainha do colmo principal de cada planta foi inoculada colocando-se um pedaço de palito colonizado pelo fungo com auxílio de uma pinça estéril. As bainhas inoculadas foram amarradas aos colmos das plantas com fitilhos de algodão. Imediatamente após a inoculação, as plantas foram transferidas para câmara de nevoeiro (temperatura de $25 \pm 2{ }^{\circ} \mathrm{C}$ e umidade relativa de $90 \pm 5 \%$ ). Avaliou-se o comprimento da lesão em cada bainha inoculada às 24,48 , 72, 96 e 120 horas após inoculação (hai), com auxílio de um paquímetro digital, e calculou-se o comprimento relativo da lesão $(\mathrm{CRL})$ dividindo-se o comprimento da lesão $(\mathrm{cm})$ pelo comprimento da bainha $(\mathrm{cm}) \times 100$.

\section{Determinação da concentração de Si na bainha}

As bainhas das plantas foram coletadas às 125 hai e secas em estufa a $65^{\circ} \mathrm{C}$ por quatro dias até atingirem peso constante. Após esse procedimento, as bainhas foram moídas em moinho tipo Wiley para determinação da concentração de Si de acordo com Korndörfer et al. (2004).

\section{Processamento das bainhas para os estudos microscópicos}

Após a avaliação da doença, um total de 20 pedaços de bainhas $\left(\approx 3 \mathrm{~cm}^{2}\right)$ contendo lesōes foram coletadas de 20 plantas de cada cultivar supridas ou não com $\mathrm{Si}$ às 24,36 , $48,72,96$ e 125 hai e colocadas em frascos de vidro contendo $10 \mathrm{ml}$ de fixador composto de glutaraldeído 2,5\% (v/v) em tampão cacodilato de sódio $0,1 \mathrm{M}(\mathrm{pH} 7,2)$. Os frascos de vidro contendo amostras compostas de cada tratamento foram cobertos com papel alumínio e armazenados em geladeira a $4^{\circ} \mathrm{C}$ durante um mês até sua utilização para os estudos microscópicos.

\section{Preparo das bainhas para microanálise de raios- $X$}

Foram retirados aleatoriamente três pedaços de bainhas dos frascos de vidro contendo amostras compostas de cada tratamento. Os pedaços de bainhas $\left(\approx 3 \mathrm{~cm}^{2}\right)$ foram seccionados em tamanhos de $0,5 \mathrm{~cm}^{2}$ e lavados em tampão cacodilato de sódio $0,1 \mathrm{M}$ (por 15 minutos, três vezes), seguidas por duas lavagens por 15 minutos em água destilada para remoção do fixador. Posteriormente, as amostras foram desidratadas em pedaços de papel e os fragmentos foram montados sobre stubs com a parte abaxial da bainha recoberta por uma fina camada de carbono (Quorum Q150 T, East Grinstead, West Sussex, Inglaterra, UK). As amostras foram examinadas no microscópio eletrônico de varredura (MEV) modelo
Cameca SX-100 EPMA, com mapeamento e microanálise de raios-X por dispersão em energia (Cameca Instruments Inc., Trumbull, CT, EUA), operando a uma tensão de $15 \mathrm{kV}$ e a uma corrente de $20 \mathrm{nA}$. Para cada tratamento, dois stubs com duas amostras de tecido de bainha foram examinados no MEV e as imagens de raios-X para cada fragmento foram obtidas.

\section{Preparo das bainhas para observação no MEV}

Foram retirados aleatoriamente três pedaços de bainhas dos frascos de vidro contendo amostras compostas de cada tratamento. Os pedaços de bainhas $\left(\approx 3 \mathrm{~cm}^{2}\right)$ foram seccionados em tamanhos de $0,5 \mathrm{~cm}^{2}$ e lavados em tampão cacodilato de sódio $0,1 \mathrm{M}$ (por 15 minutos, três vezes), pós-fixados em tetróxido de ósmio 0,5\% em água por uma hora e lavados duas vezes por 15 minutos em água destilada. Em seguida, os espécimes foram desidratados em gradiente de etanol $(30,50,70,80,95$ e 100\%), por 15 minutos cada. Após desidratação, os pedaços das bainhas foram submetidos à secagem ao ponto crítico no aparelho Critical Point Dryer (Bal-Tec, Modelo CPD030; Electron Microscopy Sciences [EMS], Hatfield, PA). Os pedaços das bainhas foram montados sobre suporte metálico (stubs) e a parte abaxial da bainha foi coberta com filme de ouro paládio por meio de pulverização catódica. As amostras foram observadas no MEV (LEO modelo VP1430; Carl Zeiss, Oberkochen, Alemanha) operado entre $15-20 \mathrm{kV}$, para obtençáo das eletromicrografias. Para cada tratamento, dois stubs com duas amostras de bainha foliar foram examinados no MEV e as imagens para cada fragmento foram obtidas.

\section{Quantificação do crescimento micelial de R. solani na superfície das bainhas}

Foram retirados aleatoriamente cinco pedaços de bainhas dos frascos de vidro contendo amostras compostas de cada tratamento. Os pedaços de bainhas $\left(\approx 3 \mathrm{~cm}^{2}\right)$ foram seccionados em tamanhos de $1 \mathrm{~cm}^{2}$ e lavados em água destilada (por 15 minutos, três vezes). Um total de 15 pedaços de bainhas $\left(\approx 1 \mathrm{~cm}^{2}\right)$ por tratamento foram colocados em frascos de vidro contendo solução de etanol $70 \%$ (vol/vol), a qual foi trocada diariamente até a remoção completa da clorofila. Para observação do crescimento micelial de $R$. solani na superfície das bainhas, os fragmentos foram corados com solução de azul de toluidina $\mathrm{O}(0,1 \%)$ e azul de Tripan $(0,1 \%)$ por 30 segundos. Os fragmentos foram lavados com água destilada três vezes para retirar o excesso de corante. A nervura central dos fragmentos de bainha (parte adaxial para cima) foi removida antes da montagem nas lâminas, adicionando-se duas gotas de uma solução de glicerina/água (2:8, vol/vol). Imagens dos pedaços de bainhas 
colonizadas por $R$ solani foram adquiridos digitalmente no modo campo claro com um microscópio Carl Zeiss Axio Imager A1 (Carl Zeiss, Jena, Thuringia, Alemanha). Para quantificação do crescimento micelial de $R$. solani na superfície das bainhas utilizaram-se as imagens digitais que foram posteriormente processadas pelo programa QUANT $^{\circledR}$ (Vale et al., 2002). Com auxílio do QUANT foi possível determinar a área, em porcentagem, colonizada por hifas de $R$. solani (coradas em azul) em relação à área total de cada fragmento de bainha. Para isso, utilizou-se a seguinte formula: área (em porcentagem) contendo crescimento micelial = área ocupada $\left(\mathrm{em} \mathrm{cm}^{2}\right)$ por hifas de $R$ solani $\times$ 100/área do fragmento da bainha. A área de cada fragmento foi padronizada em $1 \mathrm{~cm}^{2}$.

\section{Preparo das bainhas para microscopia de fluorescência}

Foram retirados aleatoriamente três pedaços de bainhas dos frascos de vidro contendo amostras compostas de cada tratamento. Os pedaços de bainhas $\left(\approx 3 \mathrm{~cm}^{2}\right)$ foram seccionados em tamanhos de $1 \mathrm{~cm}^{2}$ e lavados em água destilada (por 15 minutos, três vezes). Posteriormente, a nervura central das bainhas foi removida com auxílio de um bisturi e cortes transversais semifinos dos fragmentos das bainhas foram obtidos. Cortes semifinos foram imediatamente montados sobre lâminas de vidro contendo duas gotas de uma solução de glicerina/água (2:8, vol/vol). As amostras foram observadas inicialmente no microscópio de luz, em campo claro, procurando-se regióes necrosadas. Após essa etapa foi observada a autofluorescência dos cortes selecionados com auxílio de um microscópio Carl Zeiss Axio Imager A1 (Carl Zeiss, Jena, Thuringia, Alemanha) utilizando-se o filtro 05 (azul; 395-400 nm de excitação, divisor de feixe de 460 e $470 \mathrm{~nm}$ de emissão), de acordo com Bélanger et al. (2003). As imagens foram adquiridas digitalmente.

\section{Delineamento experimental e análise estatística dos dados}

Um experimento em esquema fatorial $2 \times 2$ composto por duas cultivares de arroz, e presença ou ausência de Si na solução nutritiva foi instalado em delineamento inteiramente casualizado com dez repetiçóes para cada tempo de amostragem. Cada repetição foi composta por um vaso plástico contendo duas plantas de arroz. Os dados foram submetidos à ANOVA e as médias dos tratamentos foram comparadas pelo teste de Tukey $(\mathrm{p} \leq 0,05)$ utilizando-se o programa SAS (Release 8,02, Level 02M0 for Windows; SAS Institute, Inc., Cary, NC).

\section{RESULTADOS}

\section{Concentração de Si na bainha}

Para as cultivares BR-Irga-409 e Labelle, a concentraçâo de $\mathrm{Si}$ nas bainhas foi significativamente maior para as plantas supridas com $\mathrm{Si}$ (2,9 dag kg-1 e 2,3 dag kg-1, respectivamente) em relação às plantas não supridas com $\mathrm{Si}\left(0,4 \mathrm{dag} \mathrm{kg}^{-1}\right.$ e 0,3 $\mathrm{dag} \mathrm{kg}{ }^{-1}$, respectivamente). Não houve diferença significativa entre as cultivares independentemente da presença ou ausência de Si na soluçáo nutritiva (dados não mostrados).

\section{Microanálise de raios-X}

Tecidos das bainhas de plantas de arroz de ambos cultivares supridas com Si (Figura 1b,d) e colonizados por R. solani apresentaram intensa deposição de $\mathrm{Si}$, ao contrário do que foi observado para as plantas não supridas com esse elemento (Figura 1a,c). A deposição de Si na superfície abaxial das bainhas de plantas de arroz supridas com Si foi similar para ambos cultivares (Figura 1b,d).

\section{Avaliação do CRL}

Não foram observados sintomas da queima das bainhas para as plantas de ambos cultivares às 24 hai (Figura 2). Para a cultivar BR-Irga-409, o CRL decresceu em 38, 24, 16 e $19 \%$ nas bainhas das plantas supridas com Si em relação às bainhas das plantas não supridas com $\mathrm{Si}$, respectivamente, às 48, 72, 96 e 120 hai (Figura 2a). Para a cultivar Labelle, o CRL foi reduzido em 31 e 30\% nas bainhas das plantas supridas com $\mathrm{Si}$ comparadas às bainhas das plantas não supridas com Si, respectivamente, às 96 e 120 hai (Figura 2b).

\section{Microscopia eletrônica de varredura}

O fungo R. solani formava almofadas de infecção na superfície abaxial das bainhas das plantas de arroz independentemente da cultivar e da presença ou ausência de $\mathrm{Si}$ (Figura 3). Foi observado menor crescimento de hifas de $R$. solani sobre o tecido das bainhas das plantas supridas com $\mathrm{Si}$ (Figura 3b,d) comparado ao das bainhas das plantas não supridas com Si (Figura 3a,c), de ambos cultivares. Bainhas das plantas da cultivar Labelle (Figura 3c,d) apresentavam maior colonização pelas hifas de $R$. solani em relação a cultivar BR-Irga-409 (Figura 3a,b), independentemente da presença ou ausência de Si na solução nutritiva.

\section{Quantificação do crescimento micelial de R. solani}

Não foi observada a presença de hifas de $R$. solani nas bainhas das plantas de ambos cultivares às 24 hai (Figura 4). O crescimento de hifas de $R$. solani foi $16 \%$ maior nos 

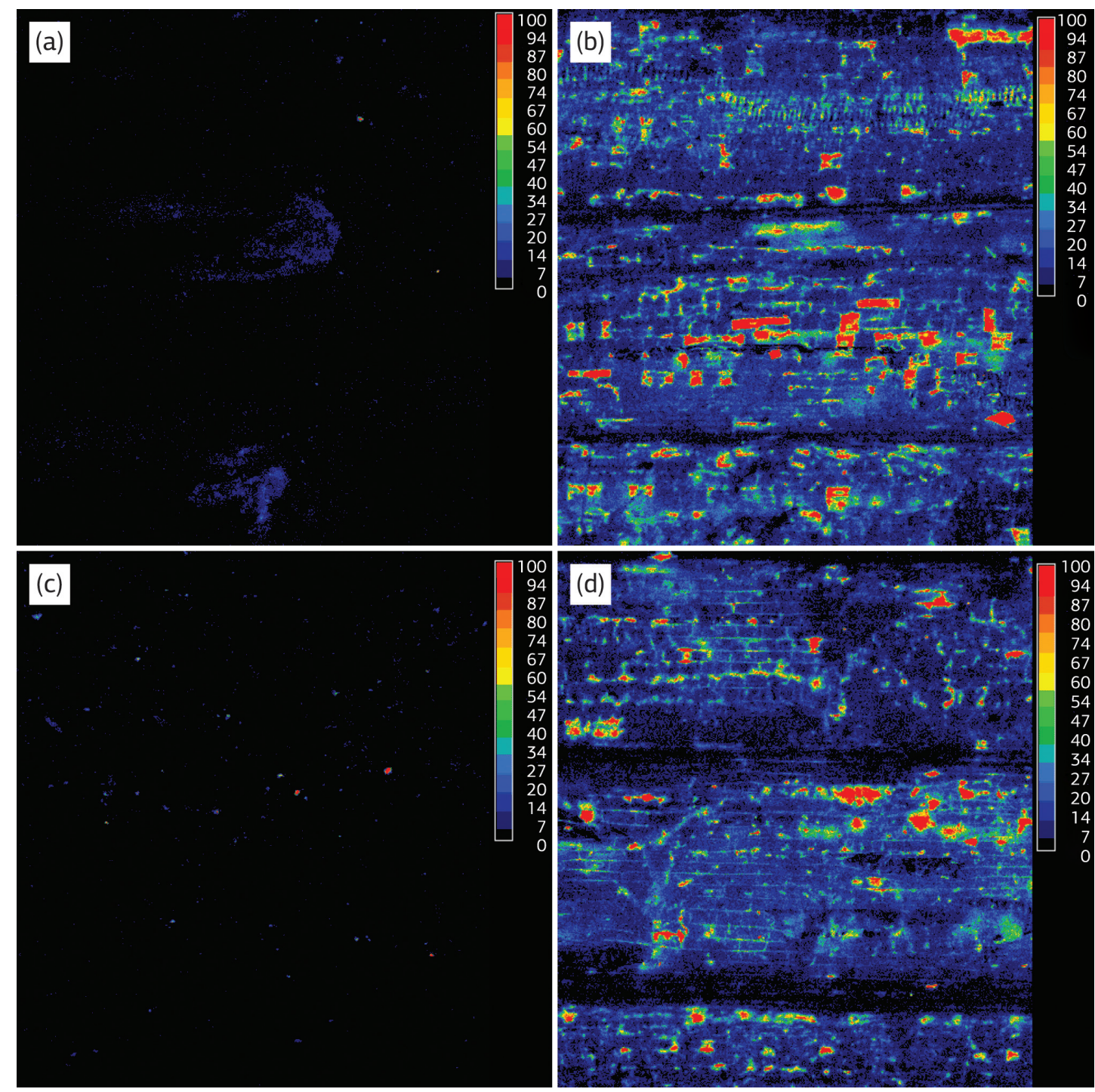

Figura 1. Deposição de silício ( $\mathrm{Si}$ ), determinada pela microanálise de raios-X, na superfície abaxial das bainhas de plantas de arroz dos cultivares BR-Irga-409 (a, b) e Labelle (c, d), crescidas na ausência ( $a, c)$ ou presença (b, d) de silício, às 125 horas após inoculação com Rhizoctonia solani; a cor vermelha indica deposição de Si e a cor preta, ausência do elemento.
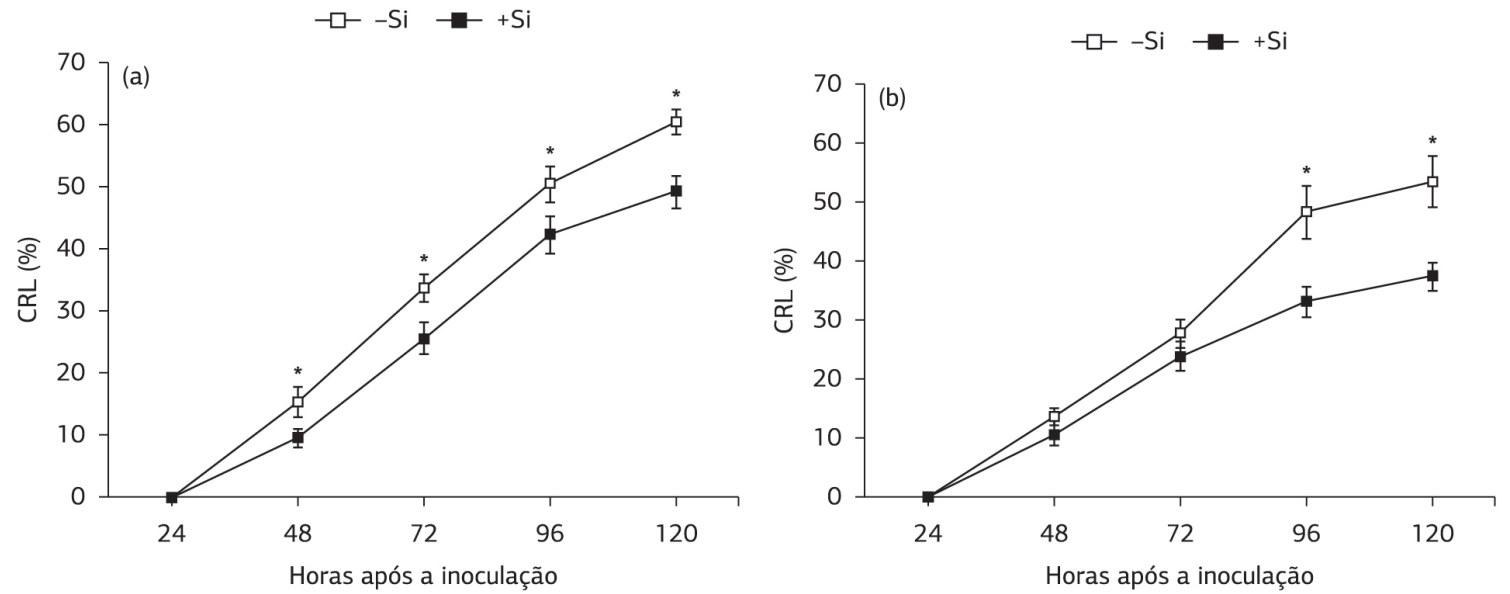

Figura 2. Comprimento relativo da lesão (CRL) da queima em bainhas de plantas de arroz dos cultivares BR-Irga-409 (a) e Labelle (b) supridas (+Si) ou náo com silício (-Si) às 24, 48, 72, 96 e 120 horas após inoculação com Rhizoctonia solani; médias dos tratamentos -Si e + Si seguidas por asterisco são significativamente diferentes $(\mathrm{p} \leq 0,05)$ pelo teste- $t$ para cada época de avaliação; as barras de erro representam o desvio padrão das médias. 

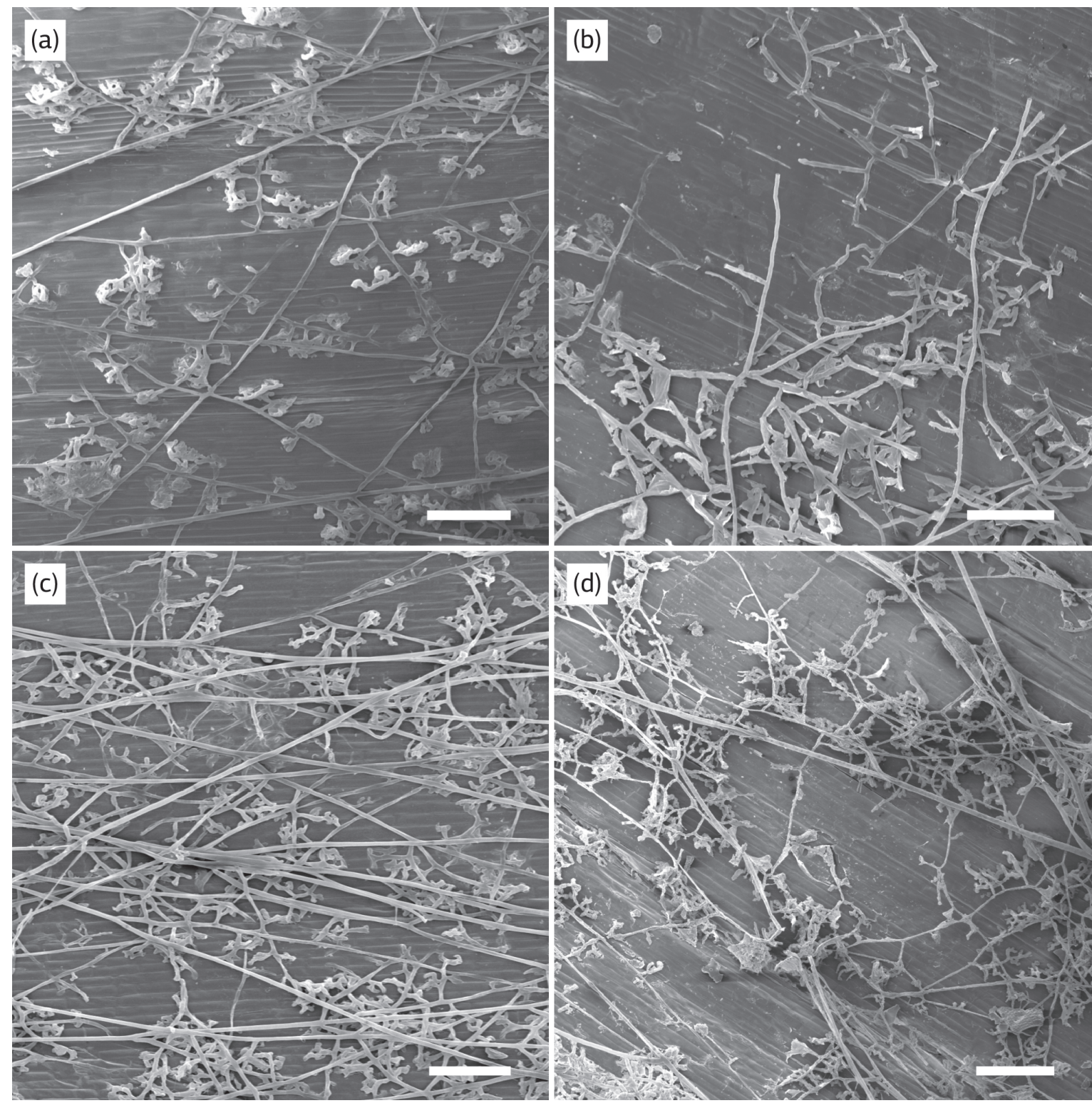

Figura 3. Eletromicrografias de varredura da superfície abaxial das bainhas de folhas de plantas de arroz dos cultivares BR-Irga-409 (a, b) e Labelle (c, d) supridas (b, d) ou não ( $a, c)$ com silício às 72 horas após inoculação com Rhizoctonia solani; barras $=200 \mu \mathrm{m}$.
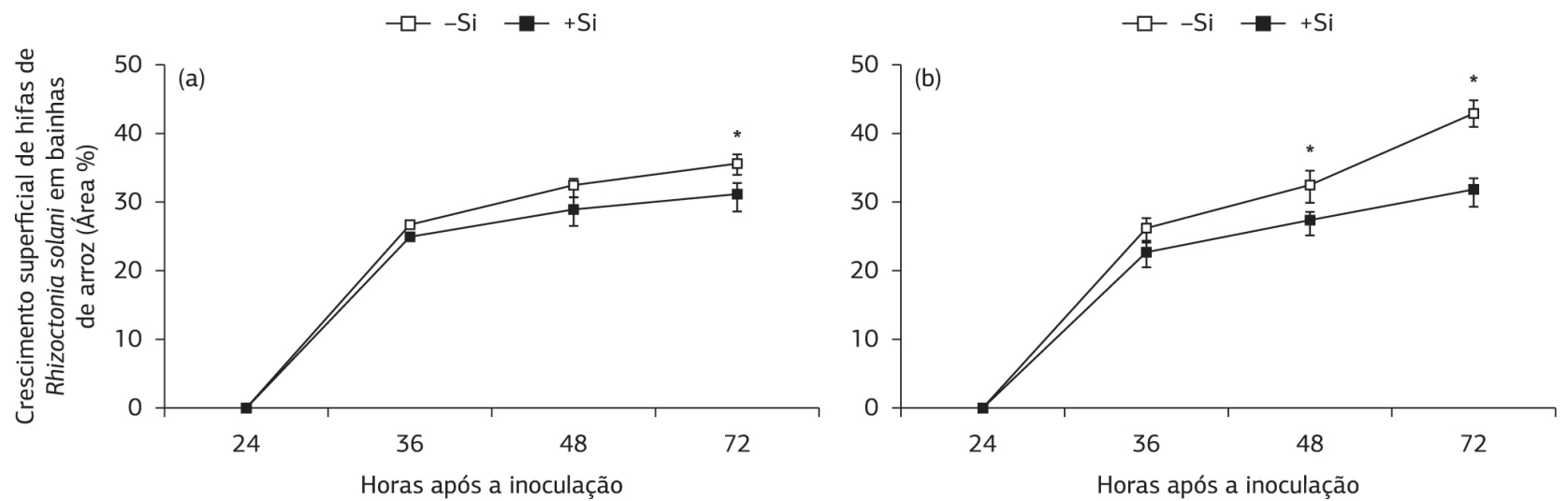

Figura 4. Crescimento superficial de hifas de Rhizoctonia solani (área em porcentagem) em fragmentos de bainhas de plantas de arroz dos cultivares BR-Irga-409 (a) e Labelle (b) supridas (+Si) ou não com silício (-Si) às 24, 36, 48 e 72 horas após inoculação; médias dos tratamentos $+\mathrm{Si}$ e $-\mathrm{Si}$ seguidas por asterisco são significativamente diferentes $(\mathrm{p} \leq 0,05)$ pelo teste- $t$ para cada época de avaliação; as barras de erro representam o desvio padrão das médias. 

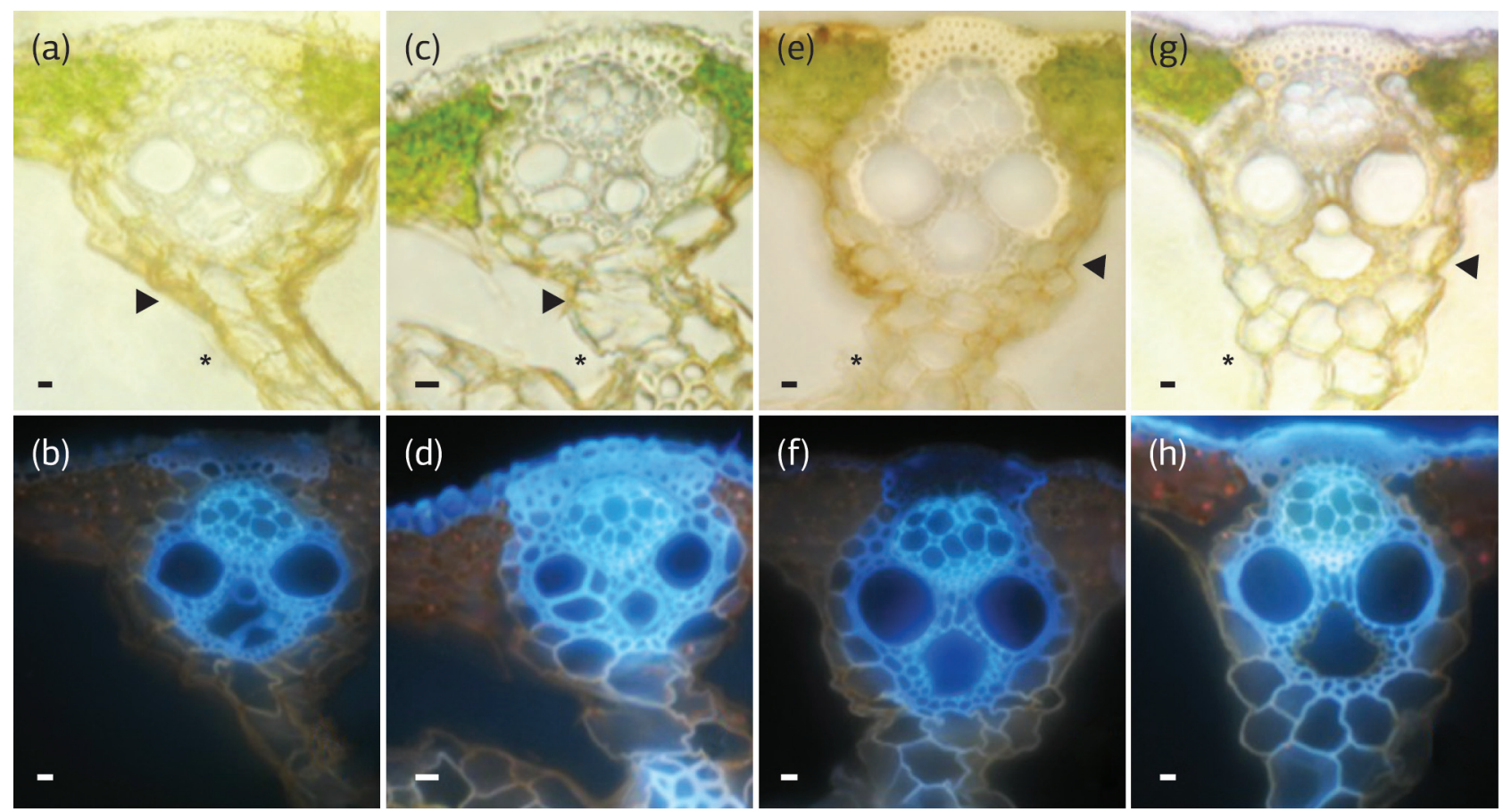

Figura 5. Microscopia de luz (a, c, e, g) e fluorescência (b, d, f, h) de cortes transversais de bainhas de plantas de arroz dos cultivares BRIrga-409 ( $\mathrm{a}, \mathrm{b}, \mathrm{c}, \mathrm{d})$ e Labelle (e, f, g, h) supridas (c, d, g, h) ou não ( $\mathrm{a}, \mathrm{b}, \mathrm{e}, \mathrm{f})$ com silício às 96 horas após inoculação com Rhizoctonia solani; os asteriscos correspondem à parte abaxial da bainha; cabeças de setas indicam áreas necrosadas; barras $=10 \mu \mathrm{m}$.

fragmentos das bainhas das plantas de arroz da cultivar BR-Irga-409 não supridas com $\mathrm{Si}$ em relação aos das bainhas das plantas supridas com Si às 72 hai (Figura 4a). Nos fragmentos das bainhas de plantas de arroz da cultivar Labelle, o crescimento de hifas de $R$. solani foi 19 e 36\% maiores nas plantas não supridas com $\mathrm{Si}$ em comparação com as bainhas das plantas supridas com $\mathrm{Si}$, respectivamente, às 48 e 72 hai (Figura 4b).

\section{Microscopia de fluorescência}

Nas secçóes obtidas das bainhas das plantas de ambas cultivares supridas com Si (Figura 5c,d,g,h), observou-se maior intensidade de autofluorescência nos tecidos próximos às regióes necróticas, tais como epiderme celular e feixes vasculares, em comparação com as secçôes das bainhas das plantas não supridas com Si (Figura 5a,b,e,f).

\section{DISCUSSÃO}

O suprimento de Si para plantas tem reconhecida importância para a redução da intensidade de várias doenças em importantes culturas comerciais, principalmente para o arroz (Cacique et al., 2013; Cruz et al., 2013, 2014; Datnoff et al., 1997; Fortunato et al., 2014; Rodrigues et al., 2003a,b; Schurt et al., 2013; Tatagiba et al., 2014). No entanto, o presente trabalho apresenta as primeiras evidências, a nível microscópico, de que a resistência do arroz à queima das bainhas é potencializada pelo Si. A alta concentração de $\mathrm{Si}$ nas bainhas das plantas de arroz das cultivares BR-Irga-409 e Labelle supridas com Si contribuiu para reduzir o desenvolvimento da queima das bainhas.

Com o auxílio da microanálise de raios-X observou-se que bainhas das plantas de arroz de ambos cultivares supridas com Si e colonizadas por $R$. solani apresentaram intensa e homogênea deposição de Si. Kim et al. (2002) sugeriram que folhas de arroz com maior concentração de Si formaram uma barreira que impediu a penetração de P. oryzae. Outros estudos utilizando microanálise de raios-X também associam alto acúmulo de Si na superfície de folhas de arroz e de trigo com maior resistência às doenças (Cacique et al., 2013; Domiciano et al., 2010; Guével et al., 2007; Rezende et al., 2009). No presente estudo, intensa e homogênea deposição de Si nas bainhas das plantas de arroz de ambos cultivares atuaram, provavelmente, como uma barreira física, afetando a penetração e a colonização de $R$. solani.

Bainhas das plantas de arroz de ambos cultivares com maior concentração de Si apresentaram reduções no progresso da queima das bainhas. Resultados semelhantes foram obtidos por Rodrigues et al. (2001, 2003a), que demonstraram que a severidade da queima das bainhas e a área abaixo da curva do progresso da extensão da lesão foram reduzidas em plantas de arroz supridas com Si. Schurt et al. (2013) também comprovaram que plantas de arroz supridas com $\mathrm{Si}$ apresentavam redução na área abaixo da curva do progresso 
da queima das bainhas de $23 \%$ em comparação com plantas náo supridas com esse elemento. No presente estudo, a alta deposição de Si nas bainhas contribuiu para reduzir os sintomas da queima das bainhas em plantas de arroz de ambos cultivares de forma semelhante à reportada por outros autores (Rodrigues et al., 2001, 2003a; Schurt et al., 2013).

Hifas de $R$. solani apresentaram menor crescimento superficial sobre as bainhas das plantas de arroz de ambos cultivares supridas com Si. Marshall \& Rush (1980) sugeriram que uma menor formação das almofadas de infecção e o limitado desenvolvimento superficial de hifas de $R$. solani sobre as bainhas de arroz foram determinantes para a redução de sintomas da queima das bainhas em cultivares de arroz consideradas resistentes. O Si pode se depositar na parede celular da epiderme das folhas de arroz podendo, assim, atuar como uma barreira física que impede ou atrasa a penetração de P. oryzae (Hayasaka et al., 2008; Kim et al., 2002; Ma \& Yamaji, 2006; Yoshida et al., 1962). Rodrigues et al. (2003b, 2004) observaram que plantas supridas com Si foram mais resistentes a infecção por P. oryzae, devido ao aumento na concentração de compostos fenólicos e fitoalexinas ao redor das hifas fúngicas. No presente estudo, a menor quantidade de hifas de $R$. solani sobre as bainhas das plantas de arroz de ambos cultivares supridas com Si podem estar associadas a uma possível barreira física proporcionada pela intensa deposição de Si nas bainhas foliares (observações da análise de raios-X) ou, possivelmente, devido a ativação de mecanismos bioquímicos que podem ter afetado a penetraçáo e a colonização do tecido de bainha por $R$. solani.

Secçôes das bainhas de folhas de plantas de arroz de ambos cultivares supridas com $\mathrm{Si}$ apresentaram intensa autofluorescência nos tecidos próximos às regiôes necrosadas por $R$. solani. Respostas específicas de defesa em tecidos de plantas infectados por patógenos podem ser obtidas pela análise da autofluorescência (Araujo et al., 2014; Fortunato et al., 2014; Koga et al., 1988; Rodrigues et al., 2005). Compostos fenólicos, fitoalexinas e lignina podem ser detectadas pelo exame de autofluorescência, pois esses compostos absorvem luz de curto comprimento de onda na faixa do ultravioleta e azul e emitem luz visível de longo comprimento de onda (Araujo et al., 2014; Fortunato et al., 2014; Koga et al., 1988; Rodrigues et al., 2005). Schurt et al. (2013) verificaram que uma maior concentraçáo de lignina (siringila/guaiacila) nas bainhas de folhas de plantas de arroz supridas com $\mathrm{Si}$ contribuiu para aumentar a resistência à queima das bainhas. Rodrigues et al. (2003b) associaram maior resistência à brusone em plantas de arroz supridas com $\mathrm{Si}$ a maior produção de compostos fenólicos em células infectadas por $P$. oryzae. No presente estudo, intensa autofluorescência nas bainhas de plantas de arroz de ambos cultivares supridas com Si indica, provavelmente, áreas incrustadas com compostos derivados da rota dos fenilpropanoides, que devem ter contribuído para reduzir os sintomas da queima das bainhas.

\section{CONCLUSÃO}

Plantas de arroz das cultivares BR-Irga-409 e Labelle supridas com $\mathrm{Si}$ apresentaram redução no CRL, além de um menor crescimento superficial de hifas de $R$. solani sobre as bainhas. Além disso, a resistência à queima das bainhas nas plantas de arroz supridas com Si parece estar associada à intensa deposição de $\mathrm{Si}$ e autofluorescência nos tecidos das bainhas colonizados por $R$. solani.

\section{AGRADECIMENTOS}

O Prof. F. A. Rodrigues agradece ao Conselho Nacional de Desenvolvimento Científico e Tecnológico - CNPq pela bolsa de produtividade em pesquisa. Os autores agradecem à Capes, ao CNPq, à Fapemig e à Finep pelos recursos financeiros. Os autores agradecem ao Núcleo de Microscopia e Microanálise da Universidade Federal de Viçosa pela utilização do MEV e equipamentos auxiliares.

\section{REFERÊNCIAS}

Araujo, L., Bispo, W. M. S., Cacique, I. S., Moreira, W. R., \& Rodrigues, F. A. (2014). Resistance in mango against infection by Ceratocystis fimbriata. Phytopathology, 104, 820-833. http://dx.doi. org/10.1094/PHYTO-11-13-0316-R. PMid:24548211.

Bélanger, R. R., Benhamou, N., \& Menzies, J. G. (2003). Cytological evidence of an active role of silicon in wheat resistance to powdery mildew (Blumeria graminis f. sp. tritici). Phytopathology, 93, 402-412. http://dx.doi.org/10.1094/PHYTO.2003.93.4.402. PMid:18944354

Cacique, I. S., Domiciano, G. P., Moreira, W. R., Rodrigues, F. A., Cruz, M. F. A., Serra, N. S., \& Català, A. B. (2013). Effect of root and leaf applications of soluble silicon on blast development in rice. Bragantia, 72, 304-309. http://dx.doi.org/10.1590/brag.2013.032.

Cruz, M. F. A., Rodrigues, F. A., Diniz, A. P. C., Moreira, M. A., \& Barros, E. G. (2013). Potassium silicate and calcium silicate on the resistance of soybean to Phakopsora pachyrhizi infection. Bragantia, 72, 373-377. http://dx.doi.org/10.1590/brag.2013.052.

Cruz, M. F. A., Araujo, L., Polanco, L. R., \& Rodrigues, F. A. (2014). Aspectos microscópicos da interação feijoeiro-Colletotrichum lindemuthianum mediados pelo silício. Bragantia, 73, 284-291. http:// dx.doi.org/10.1590/1678-4499.0139.

Datnoff, L. E., Deren, C. W., \& Snyder, G. H. (1997). Silicon fertilization for disease management of rice in Florida. Crop Protection (Guildford, Surrey), 16, 525-531. http://dx.doi.org/10.1016/S02612194(97)00033-1.

Domiciano, G. P., Rodrigues, F. A., Vale, F. X. R., Xavier-Filha, M. S., Moreira, W. R., Andrade, C. C. L., \& Pereira, S. C. (2010). Wheat resistance to spot blotch potentiated by silicon. Journal of Phytopathology, 158, 334-343. http://dx.doi.org/10.1111/j.14390434.2009.01623.x. 
Fortunato, A. A., da Silva, W. L., \& Rodrigues, F. A. (2014). Phenylpropanoid pathway is potentiated by silicon in the roots of banana plants during the infection process of Fusarium oxysporum $f$. sp. cubense. Phytopathology, 104, 597-603. http://dx.doi.org/10.1094/ PHYTO-07-13-0203-R. PMid:24350769

Guével, M. H., Menzies, J. G., \& Bélanger, R. R. (2007). Effect of root and foliar applications of soluble silicon on powdery mildew control and growth of wheat plants. European Journal of Plant Pathology, 119, 429-436. http://dx.doi.org/10.1007/s10658-007-9181-1.

Hayasaka, T., Fujii, H., \& Ishiguro, K. (2008). The role of silicon in preventing appressorial penetration by the rice blast fungus. Phytopathology, 98, 1038-1044. http://dx.doi.org/10.1094/ PHYTO-98-9-1038. PMid:18943742

Hoagland, D. R., \& Arnon, D. I. (1950). The water culture method for growing plant without soil. California Agricultural Experiment Station Circular, 347, 1-32.

Kim, S. G., Kim, K. W., Park, E. W., \& Choi, D. (2002). Siliconinduced cell wall fortification of rice leaves: a possible cellular mechanism of enhanced host resistance to blast. Phytopathology, 92, 1095-1103. http://dx.doi.org/10.1094/PHYTO.2002.92.10.1095. PMid:18944220

Koga, H., Zeyen, R. J., Bushnell, W. R., \& Ahlstrand, G. G. (1988). Hypersensitive cell death, autofluorescence, and insoluble silicon accumulation in barley leaf epidermal cells under attack by Erysiphe graminis f.sp. hordei. Physiological and Molecular Plant Pathology, 32, 395-409. http://dx.doi.org/10.1016/S0885-5765(88)80033-X.

Korndörfer, G. H., Pereira, H. S., \& Nolla, A. (2004). Análise de silício: solo, planta e fertilizante (Boletim Técnico, No. 2). Uberlândia: Universidade Federal de Uberlândia.

Li, Z., Pinson, S. R. M., Marchetti, M. A., Stansel, J. W., \& Park, W. D. (1995). Characterization of quantitative trait loci (QTLs) in cultivated rice contributing to field resistance to sheath blight (Rhizoctonia solani). Theoretical and Applied Genetics, 91, 382-388. http://dx.doi.org/10.1007/BF00220903. PMid:24169789

Ma, J. F. (2004). Role of silicon in enhancing the resistance of plants to biotic and abiotic stresses. Soil Science and Plant Nutrition, 50, 11-18. http://dx.doi.org/10.1080/00380768.2004.10408447.

Ma, J. F., \& Yamaji, N. (2006). Silicon uptake and accumulation in higher plants. Trends in Plant Science, 11, 392-397. http://dx.doi. org/10.1016/j.tplants.2006.06.007. PMid:16839801

Ma, J. F., Tamai, K., Ichii, M., \& Wu, G. F. (2002). A rice mutant defective in Si uptake. Plant Physiology, 130, 2111-2117. http:// dx.doi.org/10.1104/pp.010348. PMid:12481095

Marshall, D. S., \& Rush, M. C. (1980). Infection cushion formation on rice sheaths by Rhizoctonia solani. Phytopathology, 70, 947-950. http://dx.doi.org/10.1094/Phyto-70-947.
Ou, S. H. (1985). Rice diseases (2nd ed.) Kew: Commonwealth Mycological Institute.

Rezende, D. C., Rodrigues, F. A., Carré-Missio, V., Schurt, D. A., Kawamura, I. K., \& Korndörfer, G. H. (2009). Effect of root and foliar applications of silicon on brown spot development in rice. Australasian Plant Pathology, 38, 67-73. http://dx.doi.org/10.1071/AP08080.

Rodrigues, F. A., Datnoff, L. E., Korndörfer, G. H., Seebold, K. W., $\&$ Rush, M. C. (2001). Effect of silicon and host resistance on sheath blight development in rice. Plant Disease, 85, 827-832. http://dx.doi. org/10.1094/PDIS.2001.85.8.827.

Rodrigues, F. A., Vale, F. X. R., Korndörfer, G. H., Prabhu, A. S., Datnoff, L. E., Oliveira, A. M. A., \& Zambolim, L. (2003a). Influence of silicon on sheath blight of rice in Brazil. Crop Protection (Guildford, Surrey), 22, 23-29. http://dx.doi.org/10.1016/S0261-2194(02)00084-4.

Rodrigues, F. A., Benhamou, N., Datnoff, L. E., Jones, J. B., \& Bélanger, R. R. (2003b). Ultrastructural and cytochemical aspects of silicon-mediated rice blast resistance. Phytopathology, 93, 535-546. http://dx.doi.org/10.1094/PHYTO.2003.93.5.535. PMid:18942975

Rodrigues, F. A., McNally, D. J., Datnoff, L. E., Jones, J. B., Labbé, C., Benhamou, N., Menzies, J. G., \& Bélanger, R. R. (2004). Silicon enhances the accumulation of diterpenoid phytoalexins in rice: a potential mechanism for blast resistance. Phytopathology, 94, 177-183. http://dx.doi.org/10.1094/PHYTO.2004.94.2.177. PMid:18943541

Rodrigues, F. A., Jurick, W. M., Datnoff, L. E., Jones, J. B., \& Rollins, J. A. (2005). Silicon influences cytological and molecular events in compatible and incompatible rice-Magnaporthe grisea interactions. Physiological and Molecular Plant Pathology, 66, 144-159. http:// dx.doi.org/10.1016/j.pmpp.2005.06.002.

Schurt, D. A., Rodrigues, F. A., Carré-Missio, V., \& Soares, N. F. F. (2013). Silício alterando compostos derivados da pirólise de bainhas foliares de plantas de arroz infectadas por Rhizoctonia solani. Bragantia, 72, 52-60. http://dx.doi.org/10.1590/S0006-87052013005000020.

Tatagiba, S. D., Rodrigues, F. A., Filippi, M. C. C., Silva, G. B., \& Silva, L. C. (2014). Physiological responses of rice plants supplied with silicon to Monographella albescens infection. Journal of Phytopathology, 162, 596-606. http://dx.doi.org/10.1111/jph.12231.

Vale, F. X. R., Fernandes, E. I., Fo., \& Liberato, J. R. (2002). QUANT - A software to quantify plant disease severity. Patente INPI - 46096: Programa de Computador.

Yoshida, S., Ohnishi, Y., \& Kitagishi, K. (1962). Histochemistry of silicon in rice plant. III. The presence of cuticle-silica double layer in the epidermal tissue. Soil Science and Plant Nutrition, 8, 1-5. http:// dx.doi.org/10.1080/00380768.1962.10430982. 